Maria do Carmo Matias Freire'

Lidia Moraes Ribeiro Jordão"

Deborah Carvalho Malta"II

Silvânia Suely Caribé de Araújo Andrade ${ }^{\text {III }}$

Marco Aurelio Peres ${ }^{\text {IV }}$

Departamento de Ciências Estomatológicas Faculdade de Odontologia. Universidade Federal de Goiás. Goiânia, GO, Brasil

Programa de Pós-graduação em Odontologia. Faculdade de Odontologia. Universidade Federal de Goiás. Goiânia, GO, Brasil

III Departamento de Vigilância de Doenças e Agravos Não Transmissíveis e Promoção da Saúde. Secretaria de Vigilância em Saúde. Ministério da Saúde. Brasília, DF, Brasil

Australian Research Centre for Population Oral Health. School of Dentistry. University of Adelaide. Adelaide, Australia

Correspondence:

Lidia Moraes Ribeiro Jordão

Faculdade de Odontologia

Universidade Federal de Goiás - UFG

Av. Universitária, s/n Setor Universitário

74605-220 Goiânia, GO, Brasil

E-mail: lidmr@hotmail.com

Received: 5/7/2014

Approved: $11 / 4 / 2014$

\section{Socioeconomic inequalities and changes in oral health behaviors among Brazilian adolescents from 2009 to 2012}

\begin{abstract}
OBJECTIVE: To analyze oral health behaviors changes over time in Brazilian adolescents concerning maternal educational inequalities.
\end{abstract}

METHODS: Data from the Pesquisa Nacional de Saúde do Escolar (Brazilian National School Health Survey) were analyzed. The sample was composed of 60,973 and 61,145 students from 26 Brazilian state capitals and the Federal District in 2009 and 2012, respectively. The analyzed factors were oral health behaviors (toothbrushing frequency, sweets consumption, soft drink consumption, and cigarette experimentation) and sociodemographics (age, sex, race, type of school and maternal schooling). Oral health behaviors and sociodemographic factors in the two years were compared (Rao-Scott test) and relative and absolute measures of socioeconomic inequalities in health were estimated (slope index of inequality and relative concentration index), using maternal education as a socioeconomic indicator, expressed in number of years of study $(>11 ; 9-11 ; \leq 8)$.

RESULTS: Results from 2012, when compared with those from 2009, for all maternal education categories, showed that the proportion of people with low toothbrushing frequency increased, and that consumption of sweets and soft drinks and cigarette experimentation decreased. In private schools, positive slope index of inequality and relative concentration index indicated higher soft drink consumption in 2012 and higher cigarette experimentation in both years among students who reported greater maternal schooling, with no significant change in inequalities. In public schools, negative slope index of inequality and relative concentration index indicated higher soft drink consumption among students who reported lower maternal schooling in both years, with no significant change overtime. The positive relative concentration index indicated inequality in 2009 for cigarette experimentation, with a higher prevalence among students who reported greater maternal schooling. There were no inequalities for toothbrushing frequency or sweets consumption.

CONCLUSIONS: There were changes in the prevalences of oral health behaviors during the analyzed period; however, these changes were not related to maternal education inequalities.

DESCRIPTORS: Adolescent Behavior. Oral Hygiene. Health Knowledge, Attitudes, Practice. Dental Health Surveys. Socioeconomic Factors. Health Inequalities. 


\section{INTRODUCTION}

Monitoring health-related behaviors is useful for contributing to the planning, implementation and evaluation of health policies. Oral health is a fundamental component of overall health and must be integrated into surveillance system and health promotion actions. In addition to influencing the general heath and quality of life of individuals, the main risk factors for oral problems also contribute to the most prevalent chronic non-communicable diseases. ${ }^{23}$ For example, the frequent consumption of sugar and tobacco are associated with the etiology of caries and periodontal diseases, respectively, as well as with cardiovascular diseases and cancer. ${ }^{1,17}$

Adolescence is a stage of life in which health behaviors are established, and may even affect adulthood. ${ }^{11}$ Evaluating oral health-related behaviors of this population group in various countries, $2,7,10,12,15$ such as oral hygiene, sugar consumption and smoking, can contribute to identifying risk and protective factors, inequality in its distribution and the need for intervention. ${ }^{7}$

Performing national health surveys that include issues relevant to oral health represents a step forward in terms of health surveillance and can provide information for studying socioeconomic trends and inequalities within Brazil, as well as making international comparisons possible. In Brazil, adolescent oral health-related behaviors were included in the 2009 Pesquisa Nacional de Saúde do Escolar (PeNSE - Brazilian National School Health Survey) for the first time. ${ }^{\text {a T The results }}$ showed that lower toothbrushing frequency, more frequent sweets consumption and cigarette experimentation were associated with low levels of maternal education, ${ }^{24}$ confirming its role as a strong predictor for disease and health-related behaviors in children and adolescents. ${ }^{16,18}$

Despite some studies on the subject having been performed in Brazilian cities in recent years, ${ }^{8,14,20}$ there is still no evidence regarding behavioral changes overtime based on more than one cross-sectional study. In addition, most of these research investigations focused on oral hygiene, making it necessary to understand the characteristics of other behaviors that may influence oral health during this particular life phase.

Another important aspect concerns the social inequalities in adolescent health. ${ }^{25}$ In recent decades, more sophisticated approaches have been used to measure trends in these iniquities, ${ }^{22,26}$ and with the combined use of relative and absolute inequality measuring techniques has been recommended. ${ }^{3}$ These methods are promising in oral health research;, ${ }^{6}$ however, literature on the subject remains scarce and, until the moment of this publication, there has been no published study that used this approach regarding risk factors for oral diseases.

Studies regarding trends in the prevalence of oral health behaviors in Brazilian adolescent students and their relationship with social inequalities are necessary. In addition, they may offer an important contribution for monitoring these conditions in terms of health surveillance, and for developing health promotion strategies that are most appropriate for this population group. Changes analysis taking into account socioeconomic status may reveal the potential iniquities in the behaviors over time as well as indicate population groups which should be prioritized.

With the second PeNSE in 2012, , $^{\text {it }}$ was possible to perform comparative analysis on four factors related to oral health during this period: toothbrushing frequency, sweets consumption, soft drink consumption and cigarette experimentation. The data produced are also useful to measure socioeconomic inequalities in these behaviors, based on the main methodological strategies used in health studies. These results can help to broaden the approaches used in studies regarding inequalities in oral health and to develop integrated strategies for oral health and general health.

This study aimed to analyze the changes over time of oral health related behaviors in adolescents concerning maternal educational inequalities.

\section{METHODS}

PeNSE 2009 and 2012 databases were analyzed. PeNSE is a cross-sectional study performed with students in their ninth grade of both public and private schools. Most students were between 13 and 15 years of age. Students who did not provide information regarding their sex were excluded. The sample from the 2009 PeNSE represented 26 Brazilian capitals and the Federal District $(n=60,973$; response rate $=88.7 \%$ ), in 1,453 schools. The 2012 sample represented Brazil as a whole, with all five regions and 27 capital cities. The present study included only students from the 26 capitals and the Federal District $(\mathrm{n}=61,145$; response rate $=83.8 \%$ ) of 1,469 schools, making it possible to compare the two surveys.

Students who did not respond to questions regarding toothbrushing, sweets consumption and soft drinks, cigarette experimentation or maternal schooling were excluded, which resulted in different sample sizes for each studied behavior in each year.

\footnotetext{
a Instituto Brasileiro de Geografia e Estatística. Pesquisa Nacional de Saúde do Escolar 2009. Rio de Janeiro (RJ); 2009.

${ }^{\mathrm{b}}$ Instituto Brasileiro de Geografia e Estatística. Pesquisa Nacional de Saúde do Escolar 2012. Rio de Janeiro (RJ); 2012.
} 
The sample size in the two surveys was estimated based on the following parameters: maximum relative error of three percentage points, $95 \%$ confidence intervals and $50.0 \%$ prevalence for the various situations regarding adolescent health. The sample size used to test associations between the variables was evaluated and proved to be sufficient. Sampling in 2009 and 2012 PeNSE used the probabilistic method for selection by conglomerates at two stages: schools (primary units) and eligible classes in selected schools (ninth grade of elementary education). All students present on the day in which the questionnaire was to be undertaken were invited to participate in the research.

Sampling weights were calculated so that the collected data could represent all students enrolled in the ninth grade of elementary school who attended regular daytime classes in public and private schools, considering the different likelihoods of schools and classes being selected. These weights were obtained taking student absences into account during data collection (losses) and students who did not respond to the question regarding sex.

In order to collect data, structured self-reporting questionnaires were installed in a portable microcomputer - Personal Digital Assistant (PDA) - in 2009 and in a smartphone in 2012. The questionnaires included several adolescent health risk and protection factors. Further information regarding the sampling process and data collection can be obtained from previous publications. ${ }^{\mathrm{a}, \mathrm{b}}$

The analysis included the following behaviors related to oral health from data collected from the 2009 and 2012 PeNSE: toothbrushing frequency, weekly consumption of foods containing sugar (sweets and soft drinks) and cigarette experimentation in any moment of life. The questions that defined the outcomes were the same in both studies:

- Toothbrushing frequency: "Based on the last 30 days, how many times a day did you brush your teeth, on average?". Responses were categorized into at least twice a day and less than twice a day. ${ }^{24}$

- Sweets consumption: "Over the last seven days, on how many days did you eat treats (candies, chocolates, chewing gum, bonbons or lollipops)?". The following categories were created: low consumption (zero to four days) and high consumption (five or more days). ${ }^{13}$

- Consumption of soft drinks: "In the last seven days, on how many days did you drink soda?". The response alternatives were grouped into low consumption (zero to four days) and high consumption (five or more days). ${ }^{13}$
- Lifetime experimentation with cigarettes: "At any point in your life, have you ever smoked a cigarette, even if it were only one or two inhalations? (not counting marijuana cigarettes)". The response options were yes or no. ${ }^{4}$

For each outcome regarding oral health, the following socioeconomic and demographic variables were studied: age (11 to 13 years; 14 to 16 years; and 17 years or more), sex (male; female), self-identified race/skin color (White; Black; Yellow (Asian origin individuals); Pard $a,{ }^{\mathrm{c}}$ Indigenous), type of school (public; private) and degree of maternal schooling expressed in number of years spent in school $(>11 ; 9-11 ; \leq 8)$.

During data analysis, the prevalence of oral health-related outcomes of adolescents and their respective $95 \%$ confidence intervals were initially estimated for the 26 Brazilian state capitals and the Federal District. The Rao-Scott test was used in order to compare the proportions between 2009 and 2012 and to measure the absolute differences in each of the years in the outcomes regarding sex, age, race/skin color, type of school and maternal education.

Maternal schooling was used as an indicator for socioeconomic inequalities. The analyses were stratified by type of school (public; private) and the following adverse outcomes were analyzed: brushing teeth less than twice a day, high sweets consumption, high consumption of soft drinks and having experimented cigarettes.

Social inequalities in health are measured in several ways with there being no consensus on which one is ideal. ${ }^{26}$ However, relative and absolute measures should be used, particularly to monitor changes overtime. ${ }^{9}$ Absolute inequalities are measurements regarding difference, while relative inequality measurements regard ratios. It is possible that different and divergent results for each condition in particular can be observed, as a significant reduction in absolute inequality and an undesirable increase in relative inequality. For this study, the following health inequality measures were estimated: slope index of inequality (SII), as an absolute measure, and Relative Concentration Index (RCI), as a relative measure. ${ }^{26}$

For the SII, the mean health condition or illness of each socioeconomic group is estimated and the categories are ordered by socioeconomic status (from lowest to highest) ${ }^{26}$ This indicator considers the size of the social groups and their interpretation is the absolute difference in the health/disease status among the top and bottom categories of the social groups distribution. In this study, if the high educational level category is $10.0 \%$ of the population, the variation of individuals in this category would be from 0 (highest) to 0.10 (lowest)

c Parda means mixed race involving African ancestry. 
with a mean of 0.05 , which would be the value for this category; if the following educational category included $20.0 \%$ of the population, its variation would be between $10.0 \%$ and $30.0 \%$, with a mean of 0.2 and so on. Thus, the population is ranked and any studied population group will have the same amplitude variation, the highest level being equal to 0 and the smallest, equal to 1 . The SII can be interpreted as an absolute change in health behavior when going from the highest to the lowest level of the adopted socioeconomic indicator scale. Negative values indicate risk accumulation in groups with the worst socioeconomic indicators or the change that happens from the bottom to the top of the proportionally employed social scale in the prevalence of the illness in question.

The RCI assesses the concentration of the health or disease measurement in particular social groups, being used to measure inequality in the case of ordinal variables, such as social class and education. ${ }^{22,26}$ It constitutes one of the so-called indices of disproportionality, calculated in the same way as the Gini index. However, for it to be calculated, the groups are ranked according to their socioeconomic condition, with values ranging between -1 and +1 . The RCI is interpreted by the percentage of change among social groups or of education associated with the change in the prevalence of the outcomes. Values close to zero indicate very little inequality; negative values mean that the poorest or least educated have a higher number of negative health outcomes than would be expected for their fraction in the population. ${ }^{9}$

Data analyses were performed by using Stata version 11.0 (Stata Corp., College Station, United States), using the survey command for complex sampling. The indicators of inequality were estimated by the Health Disparities Calculator software (Division of Cancer Control and Population Sciences, Surveillance Research Program and Applied Research Program, National Cancer Institute, United States).

The first edition of PeNSE was approved at the Brazilian National Research Ethics Commission (CONEP) of the Ministry of Health (Amendment 005/2009, referring to Registration 11,537 of July $6^{\text {th }}$, 2009). The 2012 version of PeNSE was approved by CONEP (Resolution $192 / 2012$, referring to Registration 16,805 of March $27^{\text {th }}$, 2012). In both editions, the state and municipal departments of health and education were contacted, along with the administrative departments of the surveyed schools. The students' participation was voluntary.

\section{RESULTS}

Toothbrushing frequency and sweets consumption among Brazilian adolescent students changed significantly in 2012, compared with 2009 (Table 1). The proportion of individuals who reported brushing their teeth less than twice a day increased from $4.8 \%$ in 2009 to $8.2 \%$ in 2012 , with the highest rates among boys and older adolescents for the two surveyed years. In 2012, low toothbrushing frequency was more prevalent among Black students (Tables 1 and 2).

As regards high sweets consumption, the prevalence decreased from $50.9 \%$ in 2009 to $42.3 \%$ in 2012 . We observed higher prevalences among girls and younger adolescents for the two surveyed years, among Indigenous and Asian individuals in 2009 and 2012, respectively, and among public schools students in 2012 (Tables 1 and 3).

High soft drink consumption remained similar (37.2\% of adolescents in 2009 and $35.2 \%$ in 2012). Girls and older adolescents had the highest prevalence of this outcome for both years (Tables 1 and 3).

Cigarette experimentation was reported by $23.2 \%$ of the students in 2009 and by $21.8 \%$ in 2012, without any statistical significance. For both years, this result was significantly higher among older adolescents and students from public schools. In 2009, this prevalence was higher among indigenous students and, in 2012, among Black students (Tables 1 and 2).

Analyzing the prevalence of oral health behaviors according to maternal schooling (Table 4), we observed significant differences for toothbrushing frequency and cigarette experimentation in both 2009 and 2012, as well as for sweets consumption in 2009. Adolescents with less educated mothers (zero to eight years of study) showed lower toothbrushing frequency and higher prevalence of cigarette experimentation in both years as well as higher sweets consumption in 2012. Upon comparing both surveyed years, in all categories of maternal education, the proportion of adolescents with low toothbrushing frequency increased, and the proportion of those presenting high consumption of sweets and soft drinks and those reporting to have tried smoking decreased.

The assessment of the degree of maternal schooling inequalities (Table 5) showed socioeconomic inequality among adolescents from private schools regarding soft drink consumption, since the group with highest maternal schooling showed the greatest consumption for 2012 (positive SII and RCI), and also regarding cigarette experimentation, with a higher prevalence of this behavior among teenagers with mothers of higher education (indicated by positive SII and RCI) in both 2009 and 2012. However, we observed no significant change in inequalities for cigarette experimentation for the analyzed period. We observed inequality among adolescents from public schools concerning the prevalence of high soft drink consumption among students with less educated mothers (negative SII and RCI) for the two evaluated years, albeit with no significant 
Table 1. Frequency distribution of oral health-related behaviors in adolescent students from Brazilian state capitals, 2009 and 2012.

\begin{tabular}{|c|c|c|c|c|c|c|c|}
\hline \multirow{2}{*}{ Variable } & \multicolumn{3}{|c|}{2009} & \multicolumn{3}{|c|}{2012} & \multirow{2}{*}{$\mathrm{p}^{\mathrm{b}}$} \\
\hline & $\mathrm{n}$ & $\%$ & $95 \% \mathrm{Cl}^{\mathrm{a}}$ & $\mathrm{n}$ & $\%$ & $95 \% \mathrm{Cl}^{\mathrm{a}}$ & \\
\hline Sex & 57,279 & & & 61,145 & & & \\
\hline Male & & 47.5 & $45.9 ; 48.9$ & & 49.2 & $48.4 ; 49.9$ & 0.157 \\
\hline Female & & 52.6 & $51.0 ; 54.1$ & & 50.8 & $50.0 ; 51.6$ & \\
\hline Age group (years) & 57,259 & & & 60,930 & & & \\
\hline 11 to 13 & & 24.7 & $21.5 ; 28.1$ & & 19.1 & $18.5 ; 19.7$ & 0.199 \\
\hline 14 to 16 & & 72.3 & $69.3 ; 75.1$ & & 77.7 & $77.2 ; 78.4$ & \\
\hline$\geq 17$ & & 3.0 & $2.3 ; 4.1$ & & 3.5 & $3.3 ; 3.8$ & \\
\hline Race/Skin color & 56,377 & & & 61,114 & & & \\
\hline White & & 40.5 & $35.8 ; 45.3$ & & 37.7 & $37.0 ; 38.4$ & 0.220 \\
\hline Black & & 12.8 & $11.0 ; 14.8$ & & 14.2 & $13.7 ; 14.7$ & \\
\hline Asian & & 3.7 & $3.1 ; 4.6$ & & 4.5 & $4.2 ; 4.8$ & \\
\hline Pardo & & 38.9 & $35.7 ; 42.3$ & & 40.0 & $39.2 ; 40.6$ & \\
\hline Indigenous & & 4.1 & $3.4 ; 4.9$ & & 3.7 & $3.4 ; 4.0$ & \\
\hline Maternal schooling (years of study) & 46,940 & & & 50,722 & & & \\
\hline 0 to 8 & & 41.3 & $36.0 ; 46.7$ & & 38.7 & $38.0 ; 39.5$ & 0.199 \\
\hline 9 to 11 & & 33.5 & $31.7 ; 35.3$ & & 36.9 & $36.2 ; 37.7$ & \\
\hline 12 or over & & 25.3 & $19.5 ; 32.0$ & & 24.3 & $23.7 ; 25.0$ & \\
\hline Type of school & 57,279 & & & 61,145 & & & \\
\hline Private & & 20.9 & $11.0 ; 36.1$ & & 25.5 & $24.9 ; 26.1$ & 0.157 \\
\hline Public & & 79.1 & $63.9 ; 88.9$ & & 74.5 & $73.9 ; 75.1$ & \\
\hline Daily toothbrushing frequency & 55,951 & & & 60,863 & & & \\
\hline$<2$ times & & 4.8 & $4.0 ; 5.7$ & & 8.3 & $7.9 ; 8.7$ & 0.003 \\
\hline$\geq 2$ times & & 95.2 & $94.3 ; 96.0$ & & 91.7 & $91.3 ; 92.1$ & \\
\hline Weekly sweets consumption & 56,479 & & & 61,008 & & & \\
\hline Low (0 to 4 days) & & 49.1 & $46.7 ; 51.5$ & & 57.4 & $56.7 ; 58.1$ & $<0.001$ \\
\hline High (5 or more days) & & 50.9 & $48.5 ; 53.3$ & & 42.6 & $41.9 ; 43.3$ & \\
\hline Weekly soft drink consumption & 56,520 & & & 61,024 & & & \\
\hline Low (0 to 4 days) & & 62.8 & $60.6 ; 64.7$ & & 64.6 & $64.0 ; 65.2$ & 0.377 \\
\hline High (5 or more days) & & 37.2 & $35.3 ; 39.4$ & & 35.4 & $34.8 ; 36.1$ & \\
\hline Cigarette experimentation & 56,426 & & & 61,037 & & & \\
\hline Yes & & 23.2 & $21.6 ; 24.8$ & & 21.7 & $21.0 ; 22.4$ & 0.631 \\
\hline No & & 78.9 & $75.2 ; 78.4$ & & 78.2 & $77.7 ; 79.0$ & \\
\hline
\end{tabular}

a Corrected for sampling design.

${ }^{\mathrm{b}}$ Rao-Scott Test.

difference for the period. Cigarette experimentation also showed inequality in 2009 among adolescents in public schools, having a higher prevalence among students with more educated mothers (positive RCI). There was no inequality for low toothbrushing frequency or high sweets consumption.

\section{DISCUSSION}

Among the major findings of the present study are the over time increase in low toothbrushing frequency and the reduction in the sweets and soft drinks consumption, and in cigarette experimentation. Astrom and Sandal ${ }^{2}$ reported a reduction in cigarette experimentation with Norwegian adolescents from 1985 to 1997, but with an increasing trend from 1993 to 1997, with the prevalence of this behavior being almost three times greater than what was observed during this study. As in this study, there was a higher reported prevalence of cigarette experimentation among older adolescents. ${ }^{2}$ The Norwegian study ${ }^{2}$ also showed a secular trend for the increase in sweets intake and soft drinks consumption, which was 
Table 2. Toothbrushing frequency and cigarette experimentation according to characteristics of adolescent students from Brazilian state capitals, 2009 and 2012.

\begin{tabular}{|c|c|c|c|c|c|c|c|c|c|c|}
\hline \multirow{4}{*}{ Variable } & \multicolumn{10}{|c|}{ Daily toothbrushing frequency } \\
\hline & \multicolumn{5}{|c|}{2009} & \multicolumn{5}{|c|}{2012} \\
\hline & \multicolumn{2}{|c|}{ Less than twice a day } & \multicolumn{2}{|c|}{ At least twice a day } & \multirow{2}{*}{$p^{b}$} & \multicolumn{2}{|c|}{ Less than twice a day } & \multicolumn{2}{|c|}{ At least twice a day } & \multirow{2}{*}{$\mathrm{p}^{\mathrm{b}}$} \\
\hline & $\%$ & $95 \% \mathrm{Cl}^{\mathrm{a}}$ & $\%$ & $95 \% \mathrm{Cl}^{\mathrm{a}}$ & & $\%$ & $95 \% \mathrm{Cl}^{\mathrm{a}}$ & $\%$ & $95 \% \mathrm{Cl}^{\mathrm{a}}$ & \\
\hline Sex & & & & & $<0.001$ & & & & & $<0.001$ \\
\hline Male & 6.1 & $5.2 ; 7.0$ & 93.9 & $93.0 ; 94.8$ & & 9.7 & $9.0 ; 10.5$ & 90.3 & $89.5 ; 91.0$ & \\
\hline Female & 3.8 & $3.1 ; 4.6$ & 96.2 & $95.4 ; 96.9$ & & 6.6 & $6.1 ; 7.3$ & 93.4 & $92.7 ; 93.9$ & \\
\hline Age group (years) & & & & & 0.042 & & & & & 0.008 \\
\hline 11 to 13 & 4.6 & $3.9 ; 5.3$ & 95.4 & $94.7 ; 96.1$ & & 7.5 & $6.5 ; 8.6$ & 92.5 & $91.5 ; 93.5$ & \\
\hline 14 to 16 & 4.9 & $4.1 ; 5.8$ & 95.1 & $94.2 ; 95.9$ & & 8.2 & $7.6 ; 8.7$ & 91.8 & $91.3 ; 92.4$ & \\
\hline$\geq 17$ & 6.3 & $4.5 ; 8.6$ & 93.8 & $91.5 ; 95.5$ & & 11.8 & $9.2 ; 15.0$ & 88.3 & $85.0 ; 90.8$ & \\
\hline Race/Skin color & & & & & 0.187 & & & & & 0.026 \\
\hline White & 4.4 & $3.8 ; 5.2$ & 95.6 & $94.9 ; 96.2$ & & 8.6 & $7.8 ; 9.4$ & 91.4 & $90.6 ; 92.2$ & \\
\hline Black & 5.7 & $4.0 ; 8.0$ & 94.3 & $92.0 ; 96.0$ & & 9.2 & $7.9 ; 10.7$ & 90.8 & $89.4 ; 92.1$ & \\
\hline Asian & 5.9 & $3.7 ; 9.5$ & 94.0 & $90.6 ; 96.3$ & & 9.0 & $7.1 ; 11.4$ & 91.0 & $88.6 ; 92.9$ & \\
\hline Pardo & 4.8 & $4.1 ; 5.7$ & 95.2 & $94.3 ; 95.9$ & & 7.2 & $6.6 ; 7.9$ & 91.1 & $92.1 ; 93.4$ & \\
\hline Indigenous & 5.1 & $3.9 ; 6.8$ & 94.87 & $93.2 ; 96.2$ & & 8.9 & $6.8 ; 11.6$ & & & \\
\hline Type of school & & & & & 0.213 & & & & & 0.210 \\
\hline Private & 5.0 & $4.1 ; 6.0$ & 95.0 & $94.0 ; 95.9$ & & 7.7 & $6.9 ; 8.5$ & 92.3 & $91.5 ; 93.1$ & \\
\hline Public & 4.23 & $3.7 ; 5.0$ & 95.7 & $95.0 ; 96.3$ & & 8.3 & $7.8 ; 8.9$ & 91.7 & $91.1 ; 92.2$ & \\
\hline \multicolumn{11}{|c|}{ Cigarette experimentation } \\
\hline Sex & & & & & 0.309 & & & & 0.994 & 0,994 \\
\hline Male & 19.5 & $18.5 ; 20.6$ & 80.5 & $79.4 ; 81.5$ & & 21.7 & $20.7 ; 22.7$ & 78.3 & $77.4 ; 79.3$ & \\
\hline Female & 20.7 & $18.5 ; 23.1$ & 79.3 & $76.9 ; 81.5$ & & 21.7 & $20.7 ; 22.6$ & 78.3 & $77.4 ; 79.4$ & \\
\hline Age group (years) & & & & & $<0.001$ & & & & & $<0.001$ \\
\hline 11 to 13 & 13.6 & $11.5 ; 16.0$ & 86.4 & $84.0 ; 88.5$ & & 14.8 & $13.4 ; 16.4$ & 85.2 & $83.6 ; 86.6$ & \\
\hline 14 to 16 & 21.6 & $20.2 ; 23.1$ & 78.4 & $76.9 ; 79.8$ & & 22.5 & $21.7 ; 23.3$ & 77.5 & $76.7 ; 78.3$ & \\
\hline$\geq 17$ & 36.3 & $32.7 ; 40.1$ & 63.7 & $59.9 ; 67.3$ & & 40.7 & $37.3 ; 44.3$ & 59.3 & $55.7 ; 62.7$ & \\
\hline Race/Skin color & & & & & 0.010 & & & & & $<0.001$ \\
\hline White & 19.2 & $17.1 ; 21.4$ & 80.9 & $78.6 ; 82.9$ & & 19.7 & $18.6 ; 20.9$ & 80.3 & $79.1 ; 81.4$ & \\
\hline Black & 21.5 & $19.8 ; 23.3$ & 78.5 & $76.7 ; 80.2$ & & 24.6 & $22.8 ; 26.6$ & 75.4 & $73.4 ; 77.3$ & \\
\hline Asian & 19.1 & $16.7 ; 21.9$ & 80.9 & $78.1 ; 83.3$ & & 20.7 & $17.9 ; 23.8$ & 79.3 & $76.2 ; 82.1$ & \\
\hline Pardo & 20.5 & $19.3 ; 21.7$ & 79.5 & $78.3 ; 80.7$ & & 22.4 & $21.4 ; 23.5$ & 77.6 & $76.5 ; 78.6$ & \\
\hline Indigenous & 24.0 & $21.5 ; 26.6$ & 76.0 & $73.4 ; 78.5$ & & 22.1 & $19.1 ; 25.4$ & 77.9 & $74.6 ; 80.9$ & \\
\hline Type of school & & & & & $<0.001$ & & & & & $<0.001$ \\
\hline Private & 15.8 & $14.1 ; 17.7$ & 84.2 & $82.3 ; 85.9$ & & 15.2 & $14.2 ; 16.4$ & 84.8 & $83.6 ; 85.9$ & \\
\hline Public & 21.3 & $20.0 ; 22.6$ & 78.7 & $77.4 ; 80.0$ & & 23.9 & $23.0 ; 24.7$ & 76.1 & $75.3 ; 77.0$ & \\
\hline
\end{tabular}

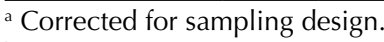

${ }^{b}$ Rao-Scott Test.

different from the findings of our study, and a small reduction in toothbrushing more than once a day.

Regarding sex-related differences, our study found consistent differences with Astrom and Sandal, ${ }^{2}$ in which girls were more inclined to have a higher toothbrushing frequency. On the other hand, Astrom and Sandal observed a greater sweets intake and soft drink consumption in males, while our study found that in females. The findings from our study show that both sexes alternated the greatest prevalences for risk behaviors.

Regarding race/skin color, our analysis highlights a higher prevalence of some risk behaviors for 
Table 3. Frequency of sweets and soft drink consumption according to characteristics of adolescent students from Brazilian state capitals, 2009 and 2012.

\begin{tabular}{|c|c|c|c|c|c|c|c|c|c|c|}
\hline \multirow{4}{*}{ Variable } & \multicolumn{10}{|c|}{ Weekly sweets consumption } \\
\hline & \multicolumn{5}{|c|}{2009} & \multicolumn{5}{|c|}{2012} \\
\hline & \multicolumn{2}{|c|}{ Low (up to 4 days) } & \multicolumn{2}{|c|}{ High (5 or more days) } & \multirow{2}{*}{$\mathrm{p}^{\mathrm{b}}$} & \multicolumn{2}{|c|}{ Low (0 to 4 days) } & \multicolumn{2}{|c|}{ High (5 or more days) } & \multirow{2}{*}{$\mathrm{p}^{\mathrm{b}}$} \\
\hline & $\%$ & $95 \% \mathrm{Cl}^{\mathrm{a}}$ & $\%$ & $95 \% \mathrm{Cl}^{\mathrm{a}}$ & & $\%$ & $95 \% \mathrm{Cl}^{\mathrm{a}}$ & $\%$ & $95 \% \mathrm{Cl}^{\mathrm{a}}$ & \\
\hline Sex & & & & & $<0.001$ & & & & & $<0.001$ \\
\hline Male & 57.4 & $55.4 ; 59.4$ & 42.6 & $40.6 ; 44.6$ & & 63.9 & $62.8 ; 65.1$ & 36.1 & $34.9 ; 37.3$ & \\
\hline Female & 41.7 & $38.5 ; 44.9$ & 58.3 & $55.1 ; 61.5$ & & 51.7 & $50.6 ; 52.8$ & 48.3 & $47.2 ; 49.5$ & \\
\hline Age group (years) & & & & & $<0.001$ & & & & & $<0.001$ \\
\hline 11 to 13 & 47.1 & $44.3 ; 50.0$ & 52.9 & $50.0 ; 55.7$ & & 57.9 & $55.9 ; 59.8$ & 42.1 & $40.2 ; 44.1$ & \\
\hline 14 to 16 & 49.5 & $47.2 ; 51.7$ & 50.5 & $48.3 ; 52.8$ & & 57.2 & $56.3 ; 58.1$ & 42.8 & $41.9 ; 43.7$ & \\
\hline$\geq 17$ & 56.3 & $53.2 ; 59.4$ & 43.7 & $40.6 ; 46.8$ & & 67.1 & $63.7 ; 70.3$ & 32.9 & $29.7 ; 36.3$ & \\
\hline Race/Skin color & & & & & 0.010 & & & & & $<0.001$ \\
\hline White & 50.3 & $47.2 ; 53.3$ & 49.8 & $46.7 ; 52.8$ & & 59.7 & $58.3 ; 61.1$ & 40.3 & $38.9 ; 41.7$ & \\
\hline Black & 50.0 & $47.8 ; 52.1$ & 50.0 & $47.9 ; 52.2$ & & 56.5 & $54.4 ; 58.7$ & 43.5 & $41.3 ; 45.6$ & \\
\hline Asian & 48.7 & $45.8 ; 51.6$ & 51.3 & $48.4 ; 54.2$ & & 54.8 & $51.2 ; 58.4$ & 45.2 & $41.6 ; 48.8$ & \\
\hline Pardo & 47.3 & $44.4 ; 50.1$ & 47.8 & $49.9 ; 55.6$ & & 56.2 & $55.0 ; 57.5$ & 43.8 & $42.5 ; 45.0$ & \\
\hline Indigenous & 49.1 & $49.3 ; 55.0$ & 50.9 & $45.0 ; 50.7$ & & 57.7 & $57.4 ; 65.2$ & 38.7 & $34.8 ; 42.6$ & \\
\hline Type of school & & & & & 0.573 & & & & & $<0.001$ \\
\hline Private & 50.1 & $46.9 ; 53.3$ & 49.9 & $46.7 ; 53.1$ & & 60.3 & $58.9 ; 61.8$ & 39.7 & $38.2 ; 41.1$ & \\
\hline Public & 48.9 & $46.1 ; 51.7$ & 51.1 & $48.3 ; 53.9$ & & 56.8 & $55.8 ; 57.8$ & 43.2 & $42.3 ; 44.2$ & \\
\hline \multicolumn{11}{|c|}{ Weekly soft drink consumption } \\
\hline Sex & & & & & 0.034 & & & & & 0.012 \\
\hline Male & 62.1 & $59.7 ; 64.5$ & 37.9 & $35.6 ; 40.3$ & & 63.8 & $62.6 ; 64.9$ & 36.3 & $35.1 ; 37.4$ & \\
\hline Female & 63.4 & $61.6 ; 65.1$ & 36.6 & $34.9 ; 38.4$ & & 65.8 & $64.7 ; 66.8$ & 34.2 & $33.2 ; 35.3$ & \\
\hline Age group (years) & & & & & $<0.001$ & & & & & $<0.001$ \\
\hline 11 to 13 & 65.2 & $63.4 ; 67.1$ & 34.8 & $32.9 ; 36.6$ & & 69.1 & $67.2 ; 70.9$ & 30.9 & $29.1 ; 32.8$ & \\
\hline 14 to 16 & 62.1 & $59.9 ; 64.2$ & 37.9 & $35.8 ; 40.1$ & & 63.9 & $63.0 ; 64.8$ & 36.1 & $35.2 ; 37.0$ & \\
\hline$\geq 17$ & 59.6 & $56.5 ; 62.7$ & 40.4 & $37.3 ; 43.5$ & & 60.8 & $57.0 ; 64.4$ & 39.2 & $35.6 ; 43.0$ & \\
\hline Race/Skin color & & & & & 0.164 & & & & & 0.156 \\
\hline White & 62.1 & $60.5 ; 63.6$ & 37.9 & $36.4 ; 39.5$ & & 64.1 & $62.7 ; 65.5$ & 35.9 & $34.6 ; 37.3$ & \\
\hline Black & 61.5 & $58.8 ; 64.2$ & 38.5 & $35.8 ; 41.3$ & & 63.6 & $61.4 ; 65.7$ & 36.4 & $34.3 ; 38.6$ & \\
\hline Asian & 65.0 & $61.2 ; 68.5$ & 35.0 & $31.5 ; 38.8$ & & 67.9 & $64.5 ; 71.1$ & 32.1 & $29.0 ; 35.5$ & \\
\hline Pardo & 63.7 & $60.9 ; 66.4$ & 36.3 & $33.6 ; 39.1$ & & 65.5 & $64.3 ; 66.7$ & 34.5 & $33.4 ; 35.7$ & \\
\hline Indigenous & 63.0 & $60.9 ; 66.4$ & 37.0 & $33.6 ; 40.5$ & & 65.1 & $61.2 ; 68.9$ & 35.2 & $31.1 ; 38.9$ & \\
\hline Type of school & & & & & 0.170 & & & & & 0.790 \\
\hline Private & 61.0 & $58.9 ; 62.9$ & 39.1 & $37.1 ; 41.1$ & & 65.0 & $63.5 ; 66.4$ & 35.1 & $33.7 ; 36.5$ & \\
\hline Public & 63.3 & $60.6 ; 65.9$ & 36.7 & $34.1 ; 39.4$ & & 64.7 & $63.8 ; 65.7$ & 35.3 & $34.3 ; 36.2$ & \\
\hline
\end{tabular}

a Corrected for sampling design.

b Rao-Scott Test.

indigenous individuals in 2009 and for Black students in 2012. At the same time, higher prevalences were observed for sweets consumption and cigarette experimentation in adolescents from public schools. It is therefore worth stressing the importance of performing regular surveys to monitor trends in health behaviors and oral health in order to integrate health interventions and target them to the most vulnerable groups.

Based on the results of this study, we suggest interventions in public schools designed to improve toothbrushing frequency and simultaneously reinforce the importance of healthy eating, including more fresh food and less processed products. For private 
Table 4. Sample distribution regarding maternal education in relation to oral health behaviors of adolescent students from Brazilian state capitals, 2009 and 2012.

\begin{tabular}{|c|c|c|c|c|c|c|c|c|c|c|c|c|c|c|}
\hline \multirow{4}{*}{ Variable } & \multicolumn{14}{|c|}{ Maternal schooling (years of study) } \\
\hline & \multicolumn{7}{|c|}{$2009(n=60,035)$} & \multicolumn{7}{|c|}{$2012(n=50,722)$} \\
\hline & \multicolumn{2}{|c|}{12 or over } & \multicolumn{2}{|c|}{9 to 11} & \multicolumn{2}{|c|}{ Up to 8} & \multirow{2}{*}{$p^{b}$} & \multicolumn{2}{|c|}{12 or over } & \multicolumn{2}{|c|}{9 to 11} & \multicolumn{2}{|c|}{ Up to 8} & \multirow{2}{*}{$p^{b}$} \\
\hline & $\%$ & $95 \% \mathrm{Cl}^{\mathrm{a}}$ & $\%$ & $95 \% \mathrm{Cl}^{\mathrm{a}}$ & $\%$ & $95 \% \mathrm{Cl}^{\mathrm{a}}$ & & $\%$ & $95 \% \mathrm{Cl}^{\mathrm{a}}$ & $\%$ & $95 \% \mathrm{Cl}^{\mathrm{a}}$ & $\%$ & $95 \% \mathrm{Cl}^{\mathrm{a}}$ & \\
\hline \multicolumn{3}{|c|}{ Daily toothbrushing frequency } & & & & & 0.002 & & & & & & & 0.033 \\
\hline $\begin{array}{l}\text { Less than } \\
\text { twice }\end{array}$ & 4.4 & $3.8 ; 5.0$ & 4.1 & $3.5 ; 4.8$ & 5.5 & $4.4 ; 6.9$ & & 7.3 & $6.4 ; 8.3$ & 7.9 & $7.1 ; 8.8$ & 9.0 & $8.1 ; 9.9$ & \\
\hline $\begin{array}{l}\text { At least } \\
\text { twice }\end{array}$ & 95.6 & $95.0 ; 96.2$ & 95.9 & $95.2 ; 96.5$ & 94.5 & $93.1 ; 95.6$ & & 92.7 & $91.7 ; 93.6$ & 92.1 & $91.2 ; 92.9$ & 91.0 & $90.0 ; 91.9$ & \\
\hline \multicolumn{3}{|c|}{ Weekly sweets consumption } & & & & & 0.020 & & & & & & & 0.433 \\
\hline $\begin{array}{l}\text { Low }(0 \text { to } \\
4 \text { days) }\end{array}$ & 50.0 & $46.8 ; 53.2$ & 47.4 & $44.9 ; 49.9$ & 49.7 & $47.5 ; 51.8$ & & 59.0 & $57.2 ; 60.8$ & 57.7 & $56.3 ; 59.1$ & 57.5 & $56.1 ; 59.0$ & \\
\hline $\begin{array}{l}\text { High ( } 5 \text { or } \\
\text { more days) }\end{array}$ & 49.9 & $46.8 ; 53.2$ & 52.6 & $50.1 ; 55.1$ & 50.3 & $48.2 ; 52.5$ & & 41.1 & $39.2 ; 42.8$ & 42.3 & $40.9 ; 43.7$ & 42.5 & $41.0 ; 43.9$ & \\
\hline \multicolumn{3}{|c|}{ Weekly soft drink consumption } & & & & & 0.105 & & & & & & & 0.105 \\
\hline $\begin{array}{l}\text { Low ( } 0 \text { to } \\
4 \text { days) }\end{array}$ & 61.0 & $58.2 ; 63.6$ & 62.5 & $60.9 ; 63.9$ & 64.3 & $60.9 ; 67.6$ & & 64.5 & $62.7 ; 66.2$ & 64.2 & $62.8 ; 65.6$ & 66.2 & $67.8 ; 67.6$ & \\
\hline $\begin{array}{l}\text { High ( } 5 \text { or } \\
\text { more days) }\end{array}$ & 39.1 & $36.4 ; 41.8$ & 37.6 & $36.1 ; 39.1$ & 35.7 & $32.4 ; 39.1$ & & 35.5 & $33.8 ; 37.3$ & 35.8 & $34.4 ; 37.3$ & 33.8 & $32.4 ; 35.2$ & \\
\hline \multicolumn{3}{|c|}{ Cigarette experimentation } & & & & & $<0.001$ & & & & & & & $<0.001$ \\
\hline Yes & 19.2 & $17.5 ; 21.1$ & 22.6 & $20.9 ; 24.4$ & 26.4 & $24.9 ; 27.9$ & & 18.5 & $17.0 ; 20.0$ & 20.8 & $19.6 ; 21.9$ & 24.8 & $23.6 ; 26.1$ & \\
\hline No & 80.8 & $78.9 ; 82.5$ & 77.4 & $75.6 ; 79.1$ & 73.6 & $72.1 ; 75.1$ & & 81.5 & $80.0 ; 83.0$ & 79.2 & $78.0 ; 80.4$ & 79.2 & $73.9 ; 76.4$ & \\
\hline
\end{tabular}

${ }^{a}$ Corrected for sampling design.

${ }^{\mathrm{b}}$ Rao-Scott Test.

Table 5. Measures of inequalities for oral health behaviors in adolescent students from private and public Brazilian state capitals' schools according to maternal education, 2009 and 2012.

\begin{tabular}{|c|c|c|c|c|c|c|}
\hline Variable & & & $\begin{array}{l}\text { Toothbrushing less } \\
\text { than twice a day }\end{array}$ & $\begin{array}{l}\text { High sweets } \\
\text { consumption }\end{array}$ & $\begin{array}{l}\text { High soft drink } \\
\text { consumption }\end{array}$ & $\begin{array}{c}\text { Cigarette } \\
\text { experimentation }\end{array}$ \\
\hline \multicolumn{7}{|l|}{ Private school } \\
\hline \multirow{4}{*}{$\begin{array}{l}\text { Absolute } \\
\text { inequality }\end{array}$} & \multirow[t]{2}{*}{2009} & SII & 2.19 & 5.51 & 1.19 & 4.85 \\
\hline & & $95 \% \mathrm{Cl}$ & $-2.18 ; 6.56$ & $-3.92 ; 14.93$ & $-6.32 ; 8.69$ & $-2.83 ; 12.52$ \\
\hline & \multirow[t]{2}{*}{2012} & SII & 0.87 & 2.10 & 7.95 & 13.68 \\
\hline & & $95 \% \mathrm{Cl}$ & $-3.10 ; 4.84$ & $-5.08 ; 9.28$ & $0.92 ; 14.98$ & $7.67 ; 19.69$ \\
\hline \multirow{4}{*}{$\begin{array}{l}\text { Relative } \\
\text { inequality }\end{array}$} & \multirow[t]{2}{*}{2009} & $\mathrm{RCl}$ & 0.07 & 0.02 & 0.01 & 0.04 \\
\hline & & $95 \% \mathrm{Cl}$ & $-0.06 ; 0.20$ & $-0.01 ; 0.04$ & $-0.02 ; 0.03$ & $-0.02 ; 0.10$ \\
\hline & \multirow[t]{2}{*}{2012} & $\mathrm{RCl}$ & 0.02 & 0.01 & 0.03 & 0.12 \\
\hline & & $95 \% \mathrm{Cl}$ & -0.060 .09 & $-0.02 ; 0.03$ & $-0.01 ; 0.06$ & $-0.07 ; 0.16$ \\
\hline \multicolumn{7}{|l|}{ Public school } \\
\hline \multirow{4}{*}{$\begin{array}{l}\text { Absolute } \\
\text { inequality }\end{array}$} & \multirow[t]{2}{*}{2009} & SII & 1.35 & -1.64 & -8.28 & 7.41 \\
\hline & & $95 \% \mathrm{Cl}$ & $-1.03 ; 3.73$ & $-10.29 ; 7.02$ & $-14.83 ;-1.73$ & $-3.47 ; 11.36$ \\
\hline & \multirow[t]{2}{*}{2012} & SII & 2.46 & -2.82 & -9.33 & -2.01 \\
\hline & & $95 \% \mathrm{Cl}$ & $-0.39 ; 5.31$ & $-7.95 ; 2.31$ & $-4.28 ;-14.38$ & $-6.70 ; 2.68$ \\
\hline \multirow{4}{*}{$\begin{array}{l}\text { Relative } \\
\text { inequality }\end{array}$} & \multirow[t]{2}{*}{2009} & $\mathrm{RCl}$ & 0.04 & -0.005 & -0.03 & 0.05 \\
\hline & & $95 \% \mathrm{Cl}$ & $-0.03 ; 0.11$ & $-0.03 ; 0.02$ & $-0.06 ; 0.01$ & $-0.02 ; 0.07$ \\
\hline & \multirow[t]{2}{*}{2012} & $\mathrm{RCl}$ & 0.024 & -0.01 & -0.04 & -0.01 \\
\hline & & $95 \% \mathrm{Cl}$ & $-0.01 ; 0.10$ & $-0.03 ; 0.01$ & $-0.06 ;-0.02$ & $-0.04 ; 0.02$ \\
\hline
\end{tabular}

SII: slope index of inequality; $\mathrm{RCl}$ : relative concentration index 
schools, the importance of tobacco control programs and actions aimed at reducing the consumption of industrialized drinks is emphasized. Our findings corroborate those from an earlier study, which showed an association between cigarette experimentation and better socioeconomic position in a private school, suggesting that this behavior during adolescence is more linked to social group patterns than to socioeconomic status. ${ }^{19}$ Concerning industrially processed drinks, there was higher average monthly expenditure on these products in households in which women had a higher income and educational attainment, ${ }^{21}$ probably because these products are considered "time savers".

According to West, ${ }^{27}$ there is relative equality in health during adolescence, since social inequalities in health decrease during this period, unlike what happens during childhood or adulthood. It has been suggested that this could occur when the effects associated with school, peer group and youth culture transpose the effects of family, environment and neighborhood, as a way to reduce or even remove class differentials in health. This effect is noticeable in this study, since regardless of position on the maternal schooling scale, the changes in the behaviors of adolescents followed the same pattern in the analyzed period, i.e., increase in low daily toothbrushing frequency and reduction in the high consumption of soft drinks and sweets and cigarette experimentation.

Despite the fact that the surveyed health behaviors were self-reported, reliability levels are generally high for most of the self-reported measures in adolescents. ${ }^{5}$

\section{REFERENCES}

1. Albandar JM, Streckfus CF, Adesanya MR, Winn DM. Cigar, pipe, and cigarette smoking as risk factors for periodontal disease and tooth loss. J Periodontol. 2000;71(12):1874-81. DOI:10.1902/jop.2000.71.12.1874

2. Astrøm AN, Samdal O. Time-trends in oral health behaviors among Norwegian adolescents: 1985-97. Acta Odontol Scand. 2001;59(4):193-200.

3. Barros AJ, Victora CG. Measuring coverage in $\mathrm{MNCH}$ : determining and interpreting inequalities in coverage of maternal, newborn, and child health interventions. PLoS Med. 2013;10(5):e1001390. DOI:10.1371/journal.pmed.1001390

4. Barreto SM, Giatti L, Casado L, Moura L, Crespo C, Malta DC. Exposição ao tabagismo entre escolares no Brasil. Cienc Saude Coletiva. 2010;15 Supl 2:3027-34. DOI:10.1590/S1413-81232010000800007

5. Brener ND, Billy JO, Grady WM. Assessment of factors affecting the validity of self- reported health-risk behavior among adolescents: evidence from the scientific literature. J Adolesc Health. 2003;33(6):436-57. DOI:10.1016/S1054-139X(03)00052-1
However, as the used data were taken from two cross-sectional studies, the inferences from this analysis are limited to changes in the prevalence of oral health behaviors and do not allow assessing causality. Because the income variable was not included in PeNSE, the question remains whether this could be a confounding factor in the inequality analysis.

Missing data is a common occurrence in scientific health research. Statistical techniques involving missing data being replaced by estimating plausible values have been suggested in order to deal with this problem (imputation). However, excluding participants who failed to respond to each variable was the chosen course of action for this study.

One of the strengths of PeNSE is that it represents all Brazilian state capitals and the Federal District, in addition to private and public schools being included. Another important aspect is that the methods employed here to measure health inequalities are the only ones that reflect their socioeconomic dimension, presenting the experience of the entire population, and being sensitive to changes in strata distribution analyzed overtime.

We conclude that the prevalences of oral health behaviors changed during the analyzed period; however, these changes were not related to inequalities in maternal schooling. It is suggested that further research should be performed to evaluate whether the reduction of the prevalence of risk behaviors over the analyzed period results from the effectiveness of specific programs carried out in schools.
6. Cheng NF, Han PZ, Gansky SA. Methods and software for estimating health disparities: the case of children's oral health. Am J Epidemiol. 2008;168(8):906-14. DOI:10.1093/aje/kwn207

7. Currie C, Zanotti C, Morgan A, Currie D, Looze $M$, Roberts $C$, et al, editors. Social determinants of health and well-being among young people. Health Behaviour in School-aged Children (HBSC) study: international report from the 2009/2010 survey. Copenhagen: WHO Regional Office for Europe; 2012. (Health Policy for Children and Adolescents, 6).

8. Freire MCM, Sheiham A, Bino YA. Hábitos de higiene bucal e fatores sociodemográficos em adolescentes. Rev Bras Epidemiol. 2007;10(4):606-14. DOI:10.1590/S1415-790X2007000400018

9. Harper S, Lynch J. Methods for measuring cancer disparities: a review using data relevant to Healthy People 2010 cancer-related objectives. Bethesda (MD): National Cancer Institute; 2006. (Surveillance Monograph Series, 6).

10. Honkala E, Kannas L, Rise J. Oral health habits of schoolchildren in 11 European countries. Int Dent J. 1990;40(4):211-7. 
11. Kelder SH, Perry CL, Klepp KI, Lytle LL. Longitudinal tracking of adolescent smoking, physical activity, and food choice behaviors. Am J Public Health. 1994;84(7):1121-6. DOI:10.2105/AJPH.84.7.1121

12. Kim HY, Kim Y, Hwang JM, Park YD. Oral health behaviours according to demographic characteristics in Korean adolescents: a national representative sample. Int Dent J. 2011;61(3):168-73. DOI: 10.1111/j.1875-595X.2011.00038.x

13. Levy RB, Castro IRR, Cardoso LO, Tavares LF, Sardinha LMV, Gomes FS, et al. Consumo e comportamento alimentar entre adolescentes brasileiros: Pesquisa Nacional de Saúde do Escolar (PeNSE), 2009. Cienc Saude Coletiva. 2010;15 Supl 2:3085-97. DOI:10.1590/S1413-81232010000800013

14. Lisboa IC, Abegg C. Hábitos de higiene bucal e uso de serviços odontológicos por adolescentes e adultos do município de Canoas, Estado do Rio Grande do Sul, Brasil. Epidemiol Serv Saude. 2006;15(4):29-39. DOI:10.5123/S1679-49742006000400004

15. Maes L, Vereecken C, Vanobbergen J, Honkala S. Tooth brushing and social characteristics of families in 32 countries. Int Dent J. 2006;56(3):159-67. DOI:10.1111/j.1875-595X.2006.tb00089.x

16. Monteiro CA, Benicio MHD, Konno SC, Silva ACF, Lima ALL, Conde WL. Causas do declínio da desnutrição infantil no Brasil, 1996-2007. Rev Saude Publica. 2009;43(1):35-43. DOI:10.1590/S0034-89102009000100005

17. Moynihan PJ, Kelly SAM. Effect on caries of restricting sugars intake: systematic review to inform WHO guidelines. J Dent Res. 2014;93(1):8-18. DOI:10.1177/0022034513508954

18. Nilsen SM, Krokstad S, Holmen TL, Westin S. Adolescents' health-related dietary patterns by parental socio-economic position, The Nord-Trøndelag Health Study (HUNT). Eur J Public Health. 2010;20(3):299-305. DOI:10.1093/eurpub/ckp137

19. Pinto DS, Ribeiro SA. Variáveis relacionadas à iniciação do tabagismo entre estudantes do ensino médio de escola pública e escola particular na cidade de Belém- PA. J Bras Pneumol. 2007;33(5):558-64. DOI:10.1590/S1806-3713200700050001

20. Santos NCN, Alves TDB, Freitas VS, Jamelli SR, Sarinho ESC. A saúde bucal de adolescentes: aspectos de higiene, de cárie dentária e doença periodontal nas cidades de Recife, Pernambuco e Feira de Santana, Bahia. Cienc Saude Coletiva. 2007;12(5):1155-66. DOI:10.1590/S1413-81232007000500012

21. Schlindwein MM, Silva ABM. Gasto domiciliar com alimentos: uma análise para a Região Centro-Oeste. Informe Gepec. 2010;14(2):129-48.

22. Schneider MC, Castillo-Salgado C, Bacallao J, Loyola E, Mujica OJ, Vidaurre M, et al. Métodos de mensuração das desigualdades em saúde. Rev Panan Salud Publica. 2002;12(6):398-414. DOI:10.1590/S1020-49892002001200006

23. Sheiham A, Watt RG. The common risk factor approach: a rational basis for promoting oral health. Community Dent Oral Epidemiol. 2000;28(6):399-406. DOI:10.1034/j.1600-0528.2000.028006399.x

24. Vettore MV, Moysés SJ, Sardinha LMV, Iser BPM. Condição socioeconômica, frequência de escovação dentária e comportamentos em saúde em adolescentes brasileiros: uma análise a partir da Pesquisa Nacional de Saúde do Escolar (PeNSE). Cad Saude Publica. 2012;28 Supl:s101-3. DOI:10.1590/S0102-311X2012001300011

25. Victora CG, Huttly SRA, Barros FC, Lombardi C, Vaughan JP. Maternal education in relation to early and late child health outcomes: findings from a Brazilian cohort study. Soc Sci Med. 1992;34(8):899-905. DOI:10.1016/0277-9536(92)90258-R

26. Wagstaff A, Paci P, Van Doorslaer E. On the measurement of inequalities in health. Soc Sci Med. 1991;33(5):545-57. DOI:10.1016/0277-9536(91)90212-U

27. West $P$. Health inequalities in the early years: is there equalisation in youth? Soc Sci Med. 1997;44(6):833-58. DOI:10.1016/S0277-9536(96)00188-8

Presented at the IX Brazilian Congress of Epidemiology, Vitória, ES, 9/9/2014.

The authors declare no conflict of interest. 